\title{
Mistakes During Colonoscopy
}

\author{
Mohamed Alshekhani* \\ Department of Gastroenterology, University of Kurdistan gastroenterology and hepatologuy, Iraq
}

Submission: March 10, 2017; Published: May 15, 2017

"Corresponding author: Mohamed Alshekhani, MBChB-CABM-FRCP-EBGH, Member of ESGE, ASGE, AGA, ACG \& ISGE, College of Medicine, Department of gastroenterology, University of Kurdistan center for gastroenterology and hepatologuy, Sulaimaniyah,Iraqi Kurdistan, Iraq, Email: shaikhanimohammad@googlemail.com

\section{Doing Colonoscopy without Proper Indication}

Colonoscopy is not without risk and has important costs and serious complications like perforation occurring in 1 out of 1000 procedures, even higher for therapeutic indications [1], which can be fatal, even may approach that of endoscopic retrograde pancreatocholangigraphy (ERCP), when involves therapeutic procedures [2,3], so the procedure should be done with proper indications \& should not be done for referrals such as constipation only or Rome- diagnosed irritable bowel syndrome or abdominal pain only without red flag signs or symptoms [4].

\section{Doing Colonoscopy without Proper Evaluation}

Gastroenterologists may receive referrals for colonoscopy from non-gastroenterologists without proper evaluation so the gastroenterologist should evaluate the patients through detailed history physical examination \& focused investigation before proceeding to colonoscopy to have in mind a clear plan what to search for and do during colonoscopy for example the need for doing terminal ilium intubation and taking random colonic biopsies for patients referred for chronic diarrhea and the colonoscopy finds no visible lesions or the need for doing ileal intubation for patients referred with chronic diarrhea with family history of inflammatory bowel disease and or having raised inflammatory markers $[5,6]$.

Doing Colonoscopy without Proper Instruction for Colonic Preparation

Colonic preparation is the corner stone for high quality colonoscopy, so the colonoscopist himself and the assistant nurse should use all means proved to increase the rate of good colonic preparation, including face to face contact verbal education of the patient by the endoscopist himself \&provision of written material \& videos [7].

Diagnosing Early Solitary Rectal Ulcer Syndrome (SRUS) as Ulcerative Proctitis

SRUS is a misnomer and it is rectal injury, hypertrophy and ulceration due to imbalance between straining \& pelvic relaxation during defecation due to functional disturbances and or redundant rectum. The resultant rectal injury varies from erythema to hypertrophy, polypoid formation \& ulceration which may be small or very large, multiple or solitary. This erynthema may be misdiagnosed as proctitutis and the patient may mislabeled and treated as ulcerative colitis specially if the biopsy result is that of non-specific colitis, if not a god history is taken from the patient, specially the presence of constipation \& excessive straining during defecation in addition to hematochesia. What complicates the problem is that isolated ulcerative proctitis of IBD may present with constipation rather than diarrhea $[8,9]$.

Diagnosing Internal Hemorrhoids as a Cause of Lower GI Bleeding without Seeing them Actively Bleeding or Seeing Stigmata of Recent Bleeding

Internal hemorrhoids are very common which affect $50 \%$ of the population and they may co-exist with other pathologies them selves may be the cause of hematochesia rather than the hemorrhoids, so it is recommended that internal hemorrhoids should not be regarded the sole cause of hematochesia unless seeing them actively bleeding or have endoscopic features of recent bleeding and a full colonoscopic evaluation or at least sigmoidoscopy (in patients under 45 years of age) are performed [10].

\section{Not Taking Random Colonic Biopsies in Patients with Chronic Diarrhea and Normal Colonoscopy}

Taking random colonic biopsies for patients referred for chronic diarrhea and the colonoscopy finds no visible lesions, is recommended to include or exclude microscopic colitis specially in elderly females and patients suspected of having celiac disease or have family history celiac disease [11].

Not Doing Ileal Intubation in Patients Presenting with Features Suggestive of Crohn's Disease

As chronic diarrhea\& abdominal pain with alrming features or family history of IBD or have raised stool or serum inflammatory markers such as CRP or stool Calprotectin [12,13]. 


\section{Not Performing Ileal Intubation in Patients Presenting with Hematochesia \& Total Normal Colonoscopy}

In patients with history of hematochesia or overt bleeding during colonoscopy and the endoscoist could not localize the bleeding to the colon every effort should be done to intubate the ileum trying to localize the bleeding to small intestinal cause like bleeding Meckle's, before resorting to angiography or tagged RBC scanning [14].

Not Considering Alternative Diagnosis Specially Tuberculosis or Behcet's Disease in Patients with Findings Suggestive of Ileocecal Crohn's Disease

The above two diseases affects the ileocecal area like Crohn's \& distinction is important specially if biolopgcal treatment is an option which may cause serious dissemination of tuberculosis if it is not properly excluded by chest radiology and sensitive assays as IGRAS and or DNA test. Behcet's disease may be differentiated by colonoscopic features or patient evaluation of the other systems affected by the disease $[15,16]$.

\section{Not Performing Digital Rectal Examination (DRE)} in All Patients \&Anoscopy Priorto Colonoscopy in Patients Susspected if Having Perianal Disease Such is Piles, Fissure ir Perinal Fistula

Perianal disease such as piles, fissure or perinal fistula may be missed during colonoscopy unless a good retroflection is done in the rctum, which is painful and not without risks of perforation, because the colonoscope is forward viewing and these lesions are located on the lateral anal walls \& hence may be missed [17].

Not Perforing Double Inspection of the Colon or Retroflexion in the Cecum To Reduce the Chance of Missing Polyps Especially During Screening Colonoscopy

Among others, double inspection of proximal colon and or retroflection in the cecum proved to increase lesions detection \& the adenoma detection rate during screening colonoscopy and aids in ileal intubation in cases of difficulties in doing ileal intubation [18].

Not Adhering to Quality Assurance Metrics for Doing a High Quality Colonoscopy

The quality metrics of high quality colonoscopy are well known \& described by many gastrointestinal endoscopy societies and without fulfilling them the colonoscopy losses its high quality characteristics [19].

Not Considering The Proximal Colon as of Cause of Melena

Melena is commonly due to an upper GIT source, but a small intestinal source or a slowly bleeding proximal colonic lesion such as tumors or angiodysplasias should be considered as a cause \& every effort should be done for cecal\&ileal intubation to detect such lesions [20].

\section{Misdliagnosing Diffuse Pseudopolyposis Of Ibdas FAP}

Sometimes during colonoscopy hundred of polyps are seen and difficulties arise in labeling the case as familial adenomatous polyposis syndrome (FAP) or pseudopolyposis due to ulcerative colitis specially if there is no history or features of ulcerative colitis or family history of FAP. Few endoscopic features may help in differentiation like the presence of colitis between polyps and more size differences between FAB polyps than IBD- associated pseudopolyps [21].

\section{Performing Polypectomy for Polyps with Features} Suggestive of Lipoma

It is mentioned that polypectomy of a colonic lipoma may carry the risk of perforation, so if a lesion found to have features of lipoma, it is better to avoid doing polypectomy specially if asymptomatic before better evaluation [22].

\section{Performing Polypectomy if the Colon is not Prepared} well

It is mentioned that doing polypectomy on unprepared or poorly prepared colon may carry the risk of colonic perforation because of the risk of the combustion of inflammable gasses present in these situations specially if $\mathrm{CO} 2$ had not been used [23].

Not Tattoing Polyps too Large to be Removed Endoscopically

It is advised to tattoo the lesions such as polyps large or difficult or advanced enough to be removed endoscopically to guide the surgeon for more easier removal specially laproscopicsurgery [24].

Failure to Consider Scattered Aphthi to be Caused By Colon Preparation Materials, to Avoid Unnecessary Biopsies and Hence Patients Anxieties \& Further Costs

Phosphate - containing colonic preparation materials are well known to cause scattered colonic aphthi, so not considering this fact may lead to considering unnecessary biopsies and hence patients anxieties \& further costs [25]. Forgetting to mention in the colonoscopy report incidental findings that may have important future implications such as internal hemorrhoids, colonicdiverticuli\& non-bleeding angiodysplasias, in case they cause future problems.

\section{References}

1. Kantsevoy SV, Bitner M, Hajiyeva G, Mirovski PM, Cox ME, et al. (2016) Endoscopic management of colonic perforations: clips versus suturing closure. Gastrointest Endosc 84(3): 487-493.

2. Chandrasekhara V, Khashab MA, Raman Muthusamy V, Acosta RD, Agrawal D, et al. (2017) Adverse events associated with ERCP. Gastrointest Endosc 85(1): 32-47.

3. Rex DK (1995) Colonoscopy: a review of its yield for cancers and adenomas by indication. Am J Gastroenterol 90(3): 353-365.

4. Lewis JD, Brown A, Localio AR, Schwartz J (2002) Initial evaluation of rectal bleeding in young persons: a cost-effectiveness analysis. Ann Intern Med 136(2): 99-110. 
5. Zins, BJ, Sandborn, WJ, Tremaine WJ (1995) Collagenous and lymphocytic colitis: subject review and therapeutic alternatives. Am J Gastroenterol 90(9): 1394-400.

6. Lewis JD, Brown A, Localio AR, Schwartz JS (2002) Initial evaluation of rectal bleeding in young persons: a cost-effectiveness analysis. Ann Intern Med 136(2): 99-110.

7. Guideline: Bowel preparation before colonoscopy. (2015) by the American Society for Gastrointestinal Endoscopy; Gastrointestinal endoscopy 81(4).

8. AlGhulayqah AL, Abu FEH, AlSohaibani FI, Almadi MA, AlMana HM, et al. (2016) Solitary Rectal Ulcer Syndrome: A Single-center Case Series. Saudi J Gastroenterol 22(6): 456-460.

9. Sharara Al, CecilioAzar C, Amr SS, Haddad M, Eloubeidi MA, et al. (2005) Solitary rectal ulcer syndrome: endoscopic spectrum and review of the literature. Gastrointest Endosc 62(5) 755-762.

10. Ganz RA (2013) The Evaluation and Treatment of Hemorrhoids: A Guide for the Gastroenterologist. Clin Gastroenterol Hepatol 11(6) 593-603.

11. Schiller LR, Pardi DS, Sellin JH (2017) Chronic Diarrhea: Diagnosis and Management; Clin Gastroenterol Hepatol 15(2): 182-193.

12. Borsch G, Schmidt G (1985) Endoscopy of the terminal ileum:Diagnostic yield in 400 consecutive examinations. Dis Colon Rectum 28(7): 499 501.

13. Neilson LJ, Bevan R, Panter S, Thomas-GS, Rees CJ (2015) Terminalileal intubation and biopsy in routine colonoscopy practice. Expert Rev Gastroenterol Hepatol 9(5): 567-577.

14. Misra SP, Dwivedi M, Misra V (2006) Ileoscopy in 39 hematochezia patients with normal colonoscopy. World J Gastroenterol 12(19): 3101-3104.

15. Kedia S, Sharma R, BopannaS, Makharia G, Ahuja V (2017) Predictive Model for Differentiating Crohn's Disease and IntestinalTuberculosis:
The Story Is Incomplete Without Imaging; Am J Gastroenterol 112(1): 188-189.

16. Yazısız V (2014) Similarities and differences between Behçet's disease and Crohn'sdisease. World J Gastrointest Pathophysiol 5(3): 228-238.

17. https://meds.queensu.ca/central/assets/modules/ts-ecg/index.html

18. Sakata S, Stevenson AR, Naidu S, Hewett DG (2017) Techniques for Terminal Ileal Intubation at Colonoscopy When Standard Maneuvers Fail. Am J Gastroenterol 112(1): 11-12.

19. Rutter MD, Senore C, Bisschops R, Domagk D, Valori R, et al. (2016) The European Society of GastrointestinalEndoscopy Quality Improvement Initiative: developing performance measures. United European Gastroenterol J 4(1): 30-41.

20. Yachimski PS, Friedman LS (2008) Gastrointestinal bleeding in the elderly; nature clinical practice gastroentrology \& heptology 5(2): 8093.

21. Gandhi AV, Malik SM, Palazzo JP (2014) Colorectal Inflammatory Pseudopolyps: A Retrospective Analysis of 70 Patients. Open Journal of Pathology 4(3): 94-100.

22. Agrawal AM, Singh KJ (2011) Symptomatic intestinal lipomas: our experience. Med J Armed Forces India 67(4): 374-376.

23. Guideline: Complications of colonoscopy. by the American Society for Gastrointestinal Endoscopy. Gastrointestinal Endoscopy 74(4) : 2011.

24. Tholoor S, sagkournis OT, Basford P, Bhandari P (2013) Managing difficult polyps: techniques and pitfalls. Ann Gastroenterol 26(2): 114121

25. Chan A, Depew W, Vanner S, (1997) Use of oral sodium phosphate colonic lavage solution by Canadian colonoscopists: Pitfalls \&complications. Can J Gastroenterol 11(4): 334-338.

Your next submission with Juniper Publishers
will reach you the below assets
- Quality Editorial service
- Swift Peer Review
- Reprints availability
- E-prints Service
- Manuscript Podcast for convenient understanding
- Global attainment for your research
- Manuscript accessibility in different formats
( Pdf, E-pub, Full Text, Audio)
- Unceasing customer service
Track the below URL for one-step submission
https://juniperpublishers.com/online-submission.php

